\title{
CONSTITUCIONALIDAD DE LA INICIATIVA PROBATORIA DEL JUEZ EN LA PROPOSICIÓN DE LA PRUEBA DE OFICIO EN EL PROCESO CIVIL
}

\author{
Víctor Roberto Obando Blanco**
}

\begin{abstract}
Resumen
Siendo el fin del proceso el interés público del Estado, el juez tiene iniciativa probatoria para la búsqueda de la convicción judicial; sin embargo, esa iniciativa se ve limitada al esclarecimiento de los hechos que las partes no han probado en forma adecuada. El Código Procesal Civil omite en el diseño de aplicación de la prueba de oficio, los límites sobre la iniciativa probatoria; omisión que deberá ser subsanada mediante una interpretación sistemática con los artículos $188^{\circ}$ y $190^{\circ}$ del Código como resultado de la interpretación jurisprudencial, y acudiendo a la doctrina procesal que ha establecido como límiles: a) La Prueba del juez se limite a los hechos controvertidos; b) Debe constar en el proceso la fuente de prueba y; c) Respecto del principio de contradicción y el derecho de defensa de las partes, permitiendo ampliar sus pruebas inicialmente propuestas.
\end{abstract}

Palabras clave: Prueba - poder discrecional - interés público del Estado derecho fundamental a la tutela jurisdiccional efectiva - hechos controvertidos - fuentes de prueba - derecho de defensa.

\begin{abstract}
Being the end of the process a public interest of the State, the judge has probatory initiative for the search of the judicial conviction, however this initiative is limited to the elucidation of the facts that the parties have not proof in a suitable way. The Civil Procedural Code avoid in the design of the application of the proofs ordered by the judge the limits on the probatory initiative, omission that must be corrected through a systematic interpretation of the articles $188^{\circ}$ and $190^{\circ}$ of the Code as a result of the legal interpretation, and going to the procedural doctrine that it has established like limits: a) The Test of the judge is limited the controversial facts; b) The source of the proof must appear in the process; and c) About the respect to the principle of contradiction and the right of defense of the parties, allowing to extend its initially proposed tests.
\end{abstract}

Key words: Proof - discretional power - public interest of the State Fundamental right of the effective jurisdictional guardianship - controversial facts - sources of proofs - right of defense.

\footnotetext{
* Texto completo de la ponencia presentada al IV Congreso Internacional de Derecho Procesal realizado en la Universidad de Lima (24/10/07).

* Juez Especializado Titular de la Corte Superior de Justicia del Callao - Poder Judicial de Perú. Profesor de Derecho Procesal Civil de la Universidad de Lima, Inca Garcilazo de la Vega y Academia de la Magistratura.
} 
1. Introducción. 2. Fundamento o razón. 3. Discusión doctrinaria. 4. Finalidad.

5. Presupuestos para su aplicación. 6. Conclusiones.

\section{INTRODUCCIÓN}

El moderno derecho de la prueba reviste una importancia crucial al erigirse en uno de los vértices más álgidos del derecho fundamental a la tutela jurisdiccional efectiva de los derechos y en donde hace pie, en concreto, la garantía de la defensa en proceso. El juez en esta materia, a decir del maestro Augusto Morello, vigila, orienta, explora y gestiona la prueba.

La línea doctrinaria que propicia dotar al juez de iniciativa probatoria ha sido recibida en un buen número de códigos procesales en América Latina, tomando como fuente el proyecto del "Código Modelo Único para Iberoamérica", elaborado por el Instituto Iberoamericano de Derecho Procesal. La legislación austriaca de 1895, que entró en vigencia el 1 de enero de 1898, junto con su autor, Franz Klein, dio comienzo a la efectiva iniciativa instructora del juez en los términos en que hoy se conoce, así como a la innovación de muchísimas instituciones. Sin embargo, existe un sector de la doctrina que se encuentra persuadido de que el juez "sustituye" la función de las partes procesales, realizando actos que son propios de estas o se embarca en una búsqueda oficiosa de la "verdad real", "contamina" de un modo insalvable la imparcialidad de su labor y quiebra directamente la garantía constitucional del debido proceso.

En el tema de la prueba de oficio, la actividad probatoria del juez se limita a esclarecer aquellos hechos que las partes no han probado en forma adecuada. En ningún caso reemplaza la actividad de las partes, solo la complementa. La iniciativa del juez procede respecto de hechos alegados por las partes pero no acreditados de manera suficiente a su criterio. Se encamina a la verificación de las cuestiones fácticas sometidas por las partes, para facilitar la decisión justa. De ahí la acertada diferenciación de Montero Aroca, quien distingue entre actos de demostración y de verificación. En los primeros se incluyen los originados por las partes y en los segundos los provenientes de la iniciativa del juzgador, aunque al final tanto los unos como los otros, confluyan en el mismo punto.

La presente intervención en panel buscará hacer algunas reflexiones sobre lo siguiente: a) La constitucionalidad de la iniciativa probatoria del juez; b) Que 
los conceptos de pruebas de oficio y carga de la prueba se complementan, vía una interpretación sistemática y; c) que la solución más idónea de lograr que el órgano jurisdiccional otorgue una efectiva tutela, siguiendo al profesor español Joan Picó I Junoy, es la que partiendo de la distinción entre fuente y medio de prueba, atribuye al juzgador iniciativa probatoria respecto de aquellas fuentes que se revelan existentes por la actuación de alguna de las partes.

Como cuestión previa al desarrollo del tema debo señalar que asistimos a una transformación institucional de la justicia desde el punto de vista constitucional a nivel mundial, en razón básicamente a tres factores: a) Las constituciones han adquirido fuerza normativa y de plena eficacia (entendida no sólo como norma política sino como norma jurídica); b) El desarrollo del Poder Judicial está vinculado con la puesta en valor de los derechos fundamentales. De ahí que el rol del juez sea entendido ya no únicamente en la aplicación de la ley al caso concreto sino como garante de los derechos fundamentales, que le otorga una amplitud para resolver; c) Apertura de las constituciones a los ordenamientos supranacionales. Los estudios de derecho procesal tienen que ser analizados en clave constitucional.

\section{FUNDAMENTO O RAZÓN}

1. Puede encontrarse únicamente en la búsqueda de la convicción judicial, el objeto de otorgar la efectiva tutela de los intereses en litigio. El profesor José Antonio Silva Vallejo al desarrollar el tema "El Sistema de la Prueba en el Proceso" respecto al concepto de prueba expresa: "Defino a la prueba como la búsqueda de la verdad en el proceso. Esta averiguación se realiza a través de los medios y de los sucedáneos pertinentes, idóneos para formar convicción en el ánimo del Juez, quien es el destinatario de la prueba y quien la aprecia a la luz de las reglas de la sana crítica"1.

2. La función jurisdiccional tiene por objeto la búsqueda de la paz social (hacer posible la convivencia social). El proceso se concibe no solo como instrumento dirigido a la tutela jurisdiccional de derechos privados, sino además como medio para cumplir una función pública del Estado.

3. La disposición de prueba de oficio constituye una norma procesal de aplicación del principio de autoridad del juez, por el cual además de los poderes de dirección formal viene a asumir poderes atinentes al objeto deducido en el proceso. El juez es la figura central del proceso (supra partes), su director. Al principio de la dirección del proceso se vincula el de la adecuación de las 
formas procesales a las exigencias sustantivas, humanas y constitucionales de la causa. Es también verdad que la adaptabilidad del proceso a las exigencias concretas no es ilimitada (Gian Antonio Micheli).

4. Conforme enseña el maestro Hernando Devis Echandía: “La finalidad del proceso consiste en la realización del derecho, lo cual no es un interés privado de las partes en el proceso, sino un interés público del Estado; vale decir, hacer que el orden jurídico se realice a cabalidad en los casos concretos, de acuerdo con la ley, la moral, los principios generales del Derecho, la equidad y la realidad de los hechos" 2 .

5. Explica el profesor Joan Picó I Junoy que el fenómeno de la "publicización" o "socialización del proceso civil" desarrollado durante el siglo XX, cuya consecuencia más relevante se concreta en el hecho de que, sin discutir la vigencia del principio dispositivo va a ponerseen tela de juicio el de aportación de parte, al menos en lo que respecta al reparto de funciones entre el juez y los litigantes y al incremento de facultades del órgano jurisdiccional, quien frente al modelo clásico del juez pasivo o inerte, pasa a ocupar una posición activa en el proceso. En la medida en que tiene asignada la función pública de resolver los conflictos, se considera que deben atribuírsele las iniciativas necesarias para lograr la máxima eficacia en su función ${ }^{3}$.

6. En consecuencia, el fenómeno de publicización o socialización puso de manifiesto la distinción entre objeto del proceso y proceso como instrumento idóneo para alcanzar la efectiva tutela por parte del Estado.

\section{DISCUSIÓN DOCTRINARIA}

1. La concepción publicística del proceso apuesta por la existencia completamente justificada en un esquema de plena colaboración y compatibilidad entre actuación oficiosa y el principio de aportación de parte.

2. De igual modo, durante la segunda mitad del siglo $X X$ surgió otro fenómeno de especial relevancia para el Derecho Procesal, que generó los postulados del "garantismo procesal". Este sector de la doctrina procesal se muestra partidario de excluir en el proceso cualquier iniciativa que suponga dirección material del juez; centra su crítica en la posible iniciativa probatoria ex oficio iudicis y en el control judicial de la buena fe procesal en la actuación de las partes.

3. Esta posición contraria a cualquier iniciativa probatoria del juez, señala básicamente lo siguiente: 
El juez civil no es un investigador, debe resolver un conflicto de intereses. Siguiendo las lecciones de Isidoro Eisner sobre la "verdad en el proceso" se argumenta: "En sentido procesal civil la prueba, en realidad, no es una investigación. El juez civil no investiga; el juez civil no va a buscar los hechos, a ver cómo fueron; sino que va a tratar de verificar, valiéndose de los elementos probatorios que le suministraron las partes (....) No haya verdad formal y verdad material; la verdad es una sola. Cuando hay verdad, es la exacta coincidencia entre la cosa y la idea que de ella se tiene, no haya otra verdad"4.

El proceso es un debate dialéctico. Se exige prueba suficiente para satisfacer al juez, que escoge una de las dos tesis, no una tercera tesis, de lo contrario se incurre en incongruencia. Al juez le es suficiente contar con la certeza, respondiendo a la pregunta: ¿a cuál de las partes se debe dar la razón con las pruebas aportadas en el proceso?

Existen dos componentes básicos para una sentencia justa: imparcialidad del juzgador; igualdad entre los contendientes.

El proceso civil es un negocio particular, que responde a las concepciones privatistas del proceso como negocio particular o relación jurídica.

4. Las objeciones que al respecto se han formulado básicamente han establecido que la mencionada iniciativa debería ajustarse a límites. Según la exposición de Joan Picó I Junoy en su obra "El derecho a la prueba en el proceso civil" 5 señala que en primer lugar la prueba practicada por el juez debe necesariamente limitarse a los hechos controvertidos o discutidos por las partes, no pudiendo el órgano jurisdiccional llevar a cabo ninguna actividad tendente a investigar o aportar hechos no alegados por las partes, ni fallar alterándolos, so pena de incurrir la sentencia en incongruencia en cuanto al modo. En segundo lugar, para que pueda atribuirse al órgano jurisdiccional la posibilidad de practicar los diversos medios probatorios, es menester que consten en el proceso las fuentes de prueba sobre las cuales tendrá lugar la posterior actividad probatoria; solo de esta forma se evita que el juez pierda su imparcialidad, así como que pueda utilizar su "conocimiento privado" al margen de los resultados que figuran en los autos, vale decir, su actuación se restringe únicamente a comprobar o verificar hechos que ya constan en la causa y nunca a investigar hechos nuevos. En tercer lugar, es necesario que en el desarrollo del medio propuesto por el órgano jurisdiccional se respete el principio de contradicción y el derecho de defensa que todo litigante posee en la ejecución de la prueba (Michelle Taruffo, Fazzalari, entre otros). De ese modo, no se vulnera ninguna de las garantías procesales 
del justiciable.

"Fuente" de prueba es un concepto extrajurídico, que se utiliza para referirse a todo elemento de la realidad anterior al proceso e independiente de él, que tiene conocimiento o representan hechos que interesan al proceso. De ella se sirven las partes para acreditar los hechos que alegan. "Medio" de prueba es un concepto jurídico y absolutamente procesal, que alude a la actividad necesaria para incorporar las fuentes de prueba al proceso; son los instrumentos necesarios que deben utilizar los sujetos procesales para suministrar certeza en el juez. La relación entre hechos y fuentes de prueba debe sujetarse al principio de congruencia.

A continuación se da una interpretación gramatical de los principales términos componentes de estos conceptos:

Prueba

Demostración de la verdad de alguna cosa o de su existencia.

Razón o argumento conque se demuestra la verdad o falsedad de una cosa.

Indicio, muestra que se da de una cosa.

Fuente

Origen de algo, causa, principio.

Documento, obra o materiales que sirven de información o de inspiración a un autor.

\section{Medio}

Lo que puede servir para determinado fin.

Diligencia o modo para conseguir una cosa.

Como puede deducirse de las acepciones expuestas, un "medio probatorio" no es más que un instrumento que sirve para probar un hecho determinado y no lo que acredita los hechos expuestos por las partes. Las partes ofrecen pruebas, es decir, aquello que va a demostrar la verdad de sus afirmaciones.

El Código Procesal Civil omite en el diseño de aplicación de la prueba de oficio la limitación sobre la iniciativa probatoria del juez; por lo que esta omisión puede ser subsanada mediante una interpretación sistemática con los artículos $188^{\circ}$ y $190^{\circ}$ del código, que regulan la finalidad, pertinencia e improcedencia de los medios probatorios; como resultado de la labor de interpretación jurisprudencial. Es conveniente disponer normativamente -en una reforma procesal- la limitación del poder de ordenar pruebas a las 
fuentes probatorias que ya existen en los autos, que evite poner en peligro la debida imparcialidad judicial, debiendo establecerse además "el respeto por el derecho de defensa de las partes".

En el artículo $429^{\circ}$.1.II de la Ley de Enjuiciamiento Civil Española, del 7 de enero de 2000, se exige que la iniciativa probatoria del juez se ciña "a los elementos probatorios cuya existencia resulte de los autos".

5. En el debate entre estas posiciones, el profesor Joan Picó I Junoy llega a una solución o postura intermedia entre ambos enfoques doctrinales, logrando así su equilibrio, pues la eficacia del proceso sin garantismo es inadmisible desde un punto de vista constitucional, y el garantismo sin eficacia tampoco es aceptable si lo que se pretende es lograr la tutela judicial más justa posible, y no puede olvidarse que la "justicia" también es un valor supremo en la mayoría de los textos constitucionales. En este mismo sentido, el jurista y procesalista peruano Juan Monroy Gálvez afirma que la confrontación entre los Ilamados "publicistas" y "garantistas" es falaz, ya que un purismo en estas tendencias no solo no es real sino que crea una falsificación del cuadro de los acontecimientos actuales. Lo que se demuestra haciendo una revisión histórica de los aportes de los principales procesalistas que han contribuido más a la constitucionalización de las garantías del proceso a pesar de no estar incluidos dentro de la corriente garantista ${ }^{6}$.

6. El profesor Jairo Parra Quijano en su ponencia titulada "La racionalidad e ideología en las pruebas de oficio", pronunciada en el IIICongreso Internacional de Derecho Procesal realizado en la Universidad de Lima en el año 2005 ${ }^{7}$, sostiene que toma partido por la ideología según la cual en el proceso se debe averiguar la verdad, para sobre ella dictar una sentencia justa. Ello supone tener un juez interventor en el proceso, con poderes que le permitan decretar prueba de oficio. No es posible pedirle a un juez que renuncie a su necesidad de información para orientar el proceso cognoscitivo, salvo que se maneje la ideología de que lo importante es dirimir el conflicto; no importa si se logra sobre la verdad o sin ella. Decretar pruebas de oficio es una necesidad psicológica que surge cuando se tiene un "vacío cognoscitivo". En la etapa de descubrimiento de la decisión judicial se emplea la lógica dialéctica, sobre todo en lo referente a los hechos; no empleamos el método deductivo. En el tema de la prueba de oficio, en ese recorrido de búsqueda de la verdad con el método inductivo surgen los vacíos y necesidades probatorias.

7. Una de las conquistas más importantes no solo del Derecho Procesal sino del constitucionalismo moderno ha consistido en la exigencia de que el juez debe motivar y fundamentar sus decisiones. El juzgador debe adecuar 
el fallo a un razonamiento determinado, conforme a las leyes de la lógica y al ordenamiento jurídico aplicable de una forma convincente y exhaustiva. Existe el derecho del justiciable de exigir que el proceso termine materializado en una declaración de certeza que tenga razonabilidad y explicitud en su fundamentación, lo que la doctrina constitucional española del Tribunal Constitucional llama, en el desarrollo del contenido del derecho a la tutela jurisdiccional efectiva, la búsqueda de los criterios jurídicos razonables.

8. Toda sentencia judicial, en el esquema de razonamiento o de la aplicación del derecho (iura novit curia), no solo debe contar con una justificación interna, que comprende la evaluación de los hechos aportados por las partes con el correlato de prueba y la evaluación del supuesto normativo al cual se le puede aplicar el supuesto de hecho, aportando una interpretación jurídica; con una justificación externa, que comprende el conocimiento del juez de la doctrina y reglas de la experiencia (valores, vivencias, desarrollo económico y social del país, contexto cultural, etcétera), y que implica una labor creativa e integradora; sino, además, el juez debe buscar el empleo de la retórica, es decir, persuadir a las partes de lo que está fallando; en resumen es una tarea interpretativa.

9. Al regular nuestro Código Procesal Civil el derecho fundamental a la tutela jurisdiccional efectiva en el artículo I del Título Preliminar, concordante con la norma del artículo $139^{\circ}$ numeral 3 de la Constitución Política, se ha privilegiado el valor procesal "eficacia". Por nuestra parte, diremos que es un derecho público y subjetivo por el que toda persona, por el solo hecho de serlo, en tanto sujeto de derechos, está facultada a exigirle al Estado tutela jurídica plena, y cuyo contenido básico comprende un "complejo de derechos": derecho de acceso de la justicia, derecho al debido proceso, derecho a una resolución fundada en derecho y el derecho a la efectividad de las resoluciones judiciales. La cualidad de "efectividad" se desprende de su interpretación, de conformidad con los tratados internacionales sobre derechos humanos, como es el caso del artículo $8^{\circ}$ de la Declaración Universal de Derechos Humanos y el artículo $25^{\circ}$ inciso 1) de la Convención Americana de Derechos Humanos, es un atributo subjetivo que responde a la necesidad de que el proceso cumpla realmente con los fines a que está llamado a cumplir, en la medida que el proceso supone el ejercicio de la función jurisdiccional del Estado.

10. La Corte Interamericana de Derechos Humanos ha utilizado diversas expresiones para referirse al asunto que ahora interesa: garantías procesales, tutela procesal efectiva, debido proceso, por ejemplo, aun cuando no se trata - conforme a un análisis exigente - de términos sinónimos. José Cafferata Nores deslinda debido proceso de derecho a la tutela jurisdiccional efectiva: 
la "identificación resulta inadecuada, no solo porque se trata de dos derechos que tienen un origen diferente (el proceso justo de origen anglosajón y la tutela jurisdiccional efectiva de la Europa Continental), sino también porque extienden su fuerza normativa a ámbitos de aplicación también diferentes. Así, mientras la tutela jurisdiccional efectiva está circunscrita a los procesos jurisdiccionales -valga la redundancia-, el proceso justo o debido proceso rige además los procedimientos administrativos, arbitrales, militares, políticos y particulares" 8 .

\section{DISCUSIÓN DOCTRINARIA}

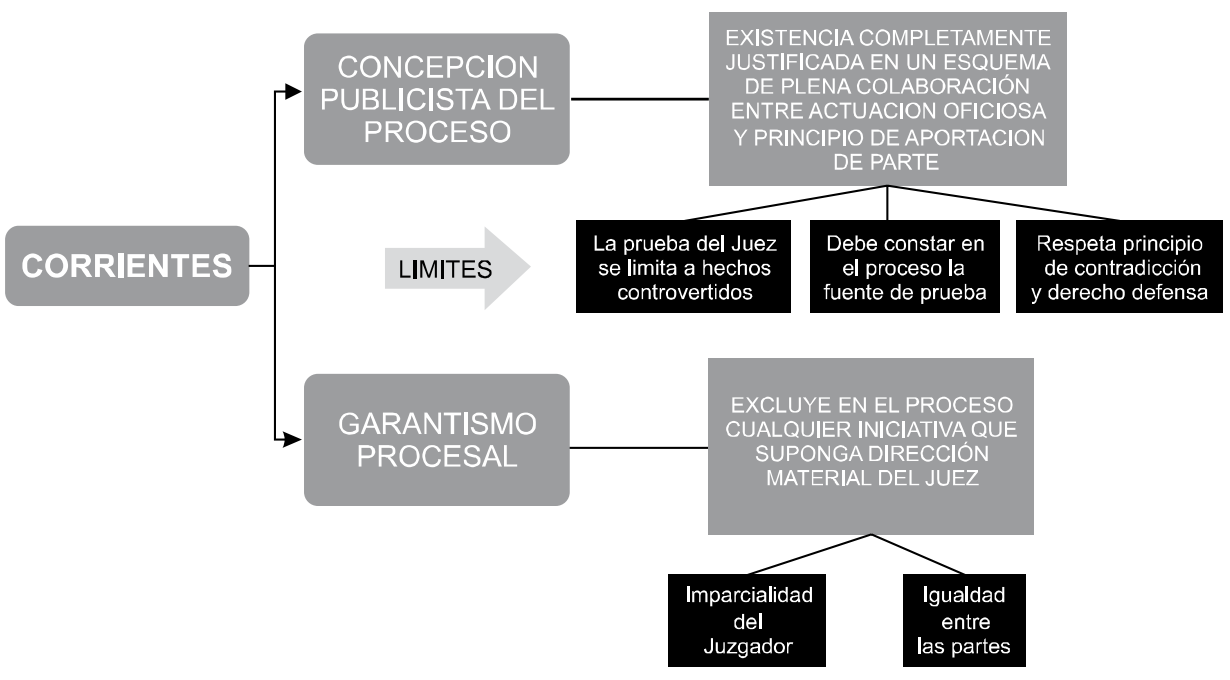

\section{FINALIDAD}

El profesor colombiano José Luis Blanco Gómezen su obra “Sistema dispositivo y prueba de oficio" ${ }^{\prime \prime}$ enuncia dos finalidades de la prueba de oficio:

a. Tiene una significación práctica, por cuanto tiende a que la norma individualizada con que termina el proceso se aproxime a ese valor jurídico supremo de la justicia, con las limitaciones que se conocen en el proceso civil, ya que el juez debe "acomodarse a las afirmaciones de las partes", como lo indica Carnelutti; en gran medida depende de las pruebas. 
b. Igualmente, busca asegurar la efectiva igualdad de las partes en el proceso -regulado por el artículo VI del Título Preliminar del Código Procesal Civil peruano-, el descubrimiento de fraudes en detrimento de terceros y evitar sentencias inhibitorias y nulidades, como lo indica el numeral 4 del artículo $37^{\circ}$ del Código Colombiano. Las pruebas de oficio facilitan el descubrimiento de las maniobras fraudulentas de aquellos que acuden a la vía expedita del proceso para causarles detrimento a terceros.

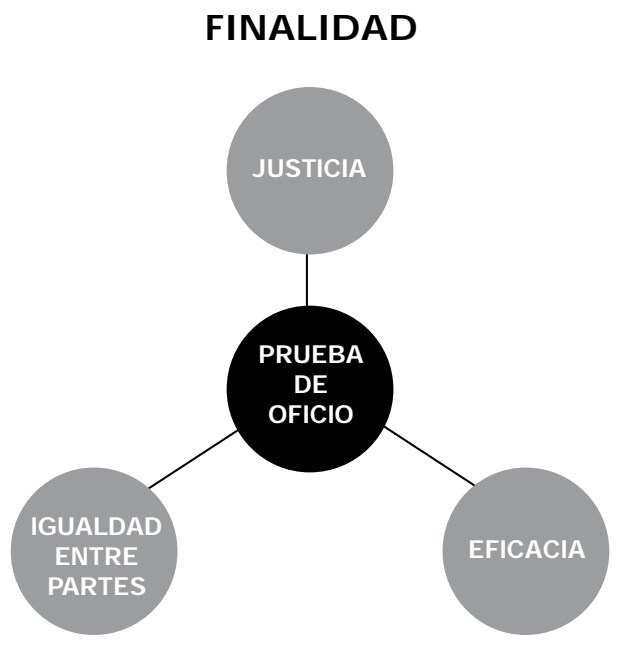

\section{V.PRESUPUESTOS PARA SU APLICACIÓN}

1. El juez tiene la facultad de actuación de medios probatorios de oficio, poder que no es ilimitado, pues de serlo es muy probable que se cause perjuicio a las partes y que el juez se parcialice. El maestro Juan Monroy Gálvez enseña que la facultad es una situación jurídica propia de las relaciones de derecho privado; el Juez, al estar por encima de las partes y al deberse a fines que superan las esferas de interés de éstas, sino de carácter general, se maneja con poderes.

2. Es un tema importante destacar que en principio, si el juez decide no actuar un medio probatorio no existirá vicio alguno por ser una función discrecional, pues la actividad de probar le corresponde a las partes y el juez solo la complementa en caso de que lo considere adecuado. Aunque también es necesario mencionar que es negativamente sintomático que los jueces nunca hagan uso de ella. Sin embargo, a este respecto, el maestro Juan Monroy Gálvez anota que hay una excepción: $¿$ Qué sucede si un juez resuelve sobre una materia respecto de la cual resultaba esencial la actuación de un medio probatorio, pero que, 
"por discreción", decidió no hacerlo? La prueba de oficio no solo se encuentra sustentada por la discrecionalidad judicial, sino también por el objeto del proceso. Es decir, hay situaciones donde el juez necesariamente debe extraer medios probatorios de los hechos alegados por las partes, aunque éstas no las hayan considerado como merecedores de probanza. En otras palabras, agrega Monroy Gálvez, si el juez encuentra que, de acuerdo a un determinado caso, es imprescindible saber si la firma es auténtica o no, debe actuar la prueba de oficio y su omisión resiente la validez de la sentencia. En este particular caso, el recurso a su "poder discrecional" no lo escuda de haber sentenciado arbitrariamente.

3. La insuficiencia de medios probatorios ofrecidos por las partes para formarse convicción sobre la materia controvertida (Artículo $194^{\circ}$ del Código Procesal Civil), esto es, cuando se requieran medios probatorios adicionales para causar convicción sobre los puntos controvertidos. De presentarse el supuesto típico de falta de probanza respecto de los hechos alegados, debe recurrir a las reglas de carga de la prueba (interpretación sistemática de los artículos $196^{\circ}$ y $200^{\circ}$ del Código Procesal Civil). Estos institutos procesales lejos de contradecirse se complementan. El juez nunca puede probar por las partes en caso de ausencia de medios probatorios; solo podrá complementar la actividad probatoria de las partes, jamás reemplazarlas porque en este supuesto estaría parcializándose.

4. La jurisprudencia en sede nacional contempla que la decisión de actuación oficiosa debe ser razonable y adecuadamente motivada (principio constitucional de motivación, garantía del justiciable). Asimismo, se ha establecido que para que un fallo se sustente en prueba de oficio esta deberá ser declarada como tal por el juez mediante la resolución correspondiente, pero no considerarla sin haberla admitido, de lo contrario la valoración por parte del juez de los medios probatorios sería arbitraria.

5. Existe jurisprudencia contradictoria en sede nacional respecto a si los jueces de segundo grado pueden ordenar al juez inferior la actuación de medios probatorios de oficio; así se ha señalado que en aplicación del principio de "independencia jurisdiccional" contenido en el artículo $16^{\circ}$ de la Ley Orgánica del Poder Judicial, ningún magistrado de instancia superior puede interferir en la actuación de los magistrados de instancias inferiores y disponer que estos actúen tales o cuáles pruebas, las que podrán ser actuadas de oficio siempre y cuando, de acuerdo a la función discrecional del juez, este las considere necesarias ${ }^{10}$. Asimismo, en esta línea la Corte Suprema de Justicia de la República ha motivado: "Estando a que nuestro ordenamiento procesal civil recoge el sistema de la libre valoración de la prueba, si la instancia superior no está de acuerdo con la apreciación de los medios probatorios efectuados por 
el inferior, tiene expedita su atribución revocatoria del fallo apelado, pero no puede disponer que este varíe la convicción a la que haya arribado, ni mucho menos ordenarle actuar pruebas de oficio por ser una función discrecional del juez, y siempre y cuando no haya arribado a una convicción sobre los hechos materia de controversia" ${ }^{11}$. Por el contrario, compulsada la jurisprudencia a nivel de Salas Superiores que legalmente no pueden generar principios jurisprudenciales, se constata la situación en la que el juez superior anula una sentencia que no tuvo en cuenta una determinada prueba y la devuelve al inferior "ordenándole" que actúe un medio probatorio de oficio. Aquí, se vulnera evidentemente el principio de independencia judicial, ya que el legislador del Código Procesal Civil establece el principio de prueba razonable por el que la apreciación de la prueba no depende de la ley, como ocurría con el sistema de la prueba tasada o de tarifa legal, sino acoge la doctrina de la valoración razonada o libre valoración o sana crítica (Artículo $197^{\circ}$ del Código Procesal Civil). El sistema de la sana crítica es un proceso racional en el que el juez debe utilizar a fondo su capacidad de análisis lógico para llegar a un juicio o conclusión producto de las pruebas actuadas en el proceso.

6. Mención aparte merece los medios probatorios ofrecidos fuera de los actos postulatorios o de forma extemporánea, siendo posible que ocurra que en el transcurso del proceso hayan nuevas pruebas, y la respuesta del juez de un ordenamiento procesal publicístico debe ser acoger la prueba que se encuentre dirigida al examen del objeto del proceso y que se considere prueba decisiva, siempre que se haya alegado en la causa petendi, pues se trata de la investigación de la verdad jurídica sobre los hechos alegados por las partes, siendo preferible, en tal materia, incurrir en un posible exceso en la admisión de pruebas que en una denegación ${ }^{12}$. La prueba de oficio permite la incorporación de tales medios probatorios, por ejemplo, el proceso sumarísimo de desalojo por causal específica de ocupación precaria, en el cual en ninguna de las sentencias se había evaluado los documentos acompañados al escrito de contestación a la demanda, si bien fueron presentados de forma extemporánea al proceso (Principio de Preclusión), tales demostrarían que la posesión que ejerce el demandado sobre el bien materia de la demanda está amparada en justo título ${ }^{13}$; debiendo observarse, además, que en el proceso de desalojo se realiza un preexamen del derecho a poseer sobre la base de ciertos elementos materiales que el demandado debe exhibir si quiere mantenerse en la posesión, no importando un examen profundo del derecho a poseer como ocurre en el proceso de conocimiento de reivindicación.

7. Se ha sostenido una "aparente incompatibilidad" entre la facultad discrecional del juez para ordenar la actuación de pruebas de oficio con posterio- 
ridad al momento procesal que le correspondía frente al principio de preclusión, quedando librado a la "discreción" del juez que podrá admitir la prueba o simplemente no admitirla, afirmando que en este caso "no se está ante una iniciativa probatoria del juez, fundada, como dice el artículo $194^{\circ}$ del Código Procesal Civil, en la insuficiencia de los medios probatorios por las partes, sino ante el ejercicio de un poder discrecional del juez (no establecido en el Código Procesal Civil) de dejar de lado las preclusiones probatorias"14; frente a esta posición se ha llegado a afirmar que el principio de preclusión dispone la tramitación del proceso de manera tal que las partes tienen la carga de realizar determinados actos en fases determinadas, de modo que por aplicación del principio quedan firmes los actos realizados en tiempo útil y extinguidas las facultades no ejercidas; el principio de eventualidad o preclusión de la prueba persigue impedir que se sorprenda a una de las partes en conflicto con medios probatorios de último momento incorporados por la otra parte, que no alcance a controvertir, o que se propongan cuestiones sobre las cuales no pueda ejercitar eficazmente su defensa, así su inobservancia implica la pérdida de oportunidad para ejecutar un acto procesal, pero en modo alguno dicho principio limita, impide o colisiona con la facultad conferida al juzgador en el artículo $194^{\circ}$ del Código Procesal Civil ${ }^{15}$.

\section{PRESUPUESTOS}

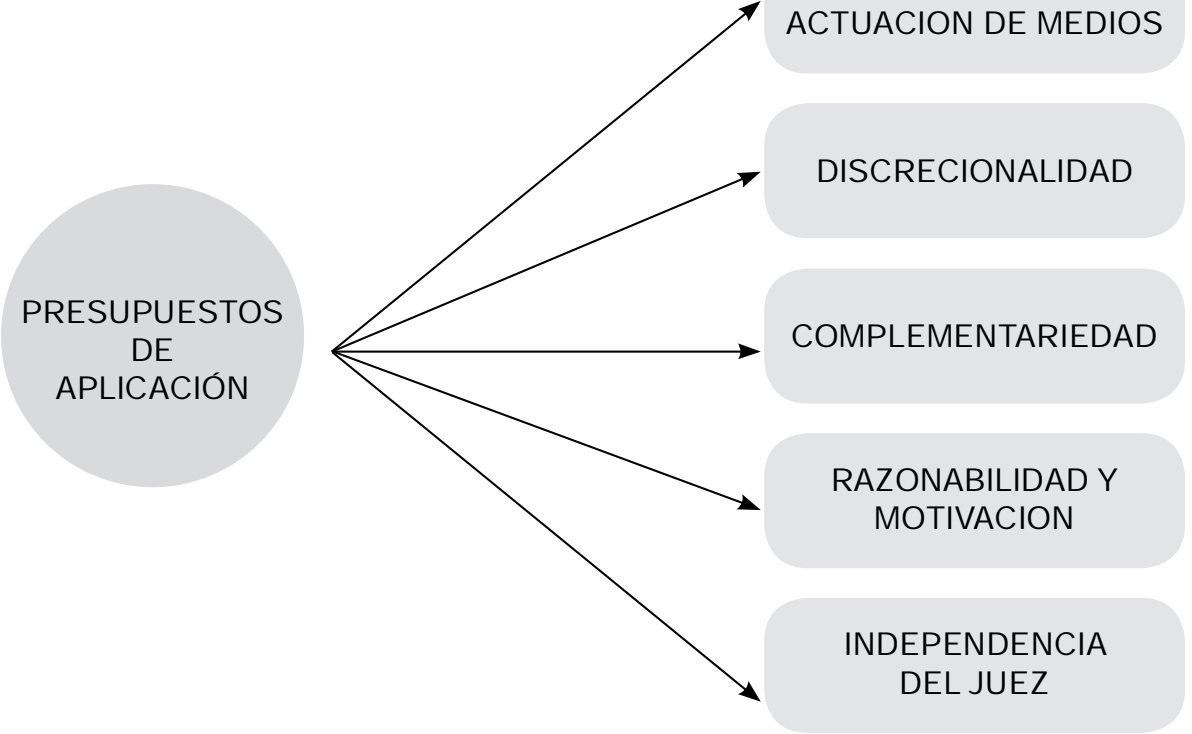

PODER DE

ACTUACION DE MEDIOS
DISCRECIONALIDAD

RAZONABILIDAD Y MOTIVACION

DEPENDENCIA DEL J UEZ 


\section{CONCLUSIONES}

1. Lo trascendente en el tema de la prueba de oficio es establecer cuáles son los límites a la iniciativa probatoria del juez; estos son: a) Que se limite a los hechos controvertidos o discutidos en el proceso -por lo que se protege el principio dispositivo-, so pena de incurrir la sentencia en incongruencia en cuanto al modo; b) Que se limite a las fuentes probatorias que ya consten en la causa -impidiendo así una actuación inquisitoria, susceptible de vulnerar la debida imparcialidad judicial y; c) Que se permita el ejercer el derecho de defensa a las partes, ampliando sus pruebas inicialmente propuestas. Observemos que el derecho a utilizar los medios de prueba pertinentes constituye un derecho fundamental, inseparable del derecho de defensa.

2. El requisito de razonabilidad excluye la arbitrariedad en la aplicación de la norma procesal. La iniciativa probatoria del juez en la proposición de la prueba de oficio es, en principio, constitucionalmente admisible, en tanto y en cuanto observe los presupuestos para su aplicación señalados en la ley procesal y se ajuste a los límites desarrollados por la doctrina procesal para el caso peruano (diseño de aplicación); además, la decisión judicial que ordene de oficio la actuación de un medio probatorio debe cumplir la exigencia constitucional de la motivación, es decir, debe ser razonable y adecuadamente motivada.

3. Nuestro Código Procesal Civil omite en el diseño de aplicación de la prueba de oficio la limitación sobre la iniciativa probatoria del juez; por lo que esta omisión puede ser subsanada mediante una interpretación sistemática con los artículos $188^{\circ}$ y $190^{\circ}$ del Código, que regulan la finalidad, pertinencia e improcedencia de los medios probatorios como resultado de la labor de interpretación jurisprudencial. Es conveniente disponer normativamente -en una reforma procesal- la limitación del poder de ordenar pruebas a las fuentes probatorias que ya existen en los autos, que evite poner en peligro la debida imparcialidad judicial, debiendo establecerse además "el respeto por el derecho de defensa de las partes".

4. Las tendencias de la jurisprudencia peruana permiten la incorporación de medios probatorios ofrecidos extemporáneamente cuando tengan vital importancia en el examen del objeto del proceso, siempre que se haya alegado en la causa petendi. Asimismo, existe jurisprudencia del Supremo Tribunal que hace prevalecer el principio de independencia judicial, en el caso de que los órganos jurisdiccionales revisores o de segundo grado anulen las sentencias señalándole al juez de primer grado el mensaje concreto que debió de oficio actuar un determinado medio probatorio o con el mensaje general 
Víctor Roberto Obando Blanco

Constitucionalidad de la iniciativa probatoria del juez en

la proposición de la prueba de oficio en el proceso civil

y abstracto que debió haber hecho uso de la facultad dispuesta en el artículo $194^{\circ}$ del Código Procesal Civil. Lo trascendente es saber que decretar pruebas de oficio es una necesidad psicológica que surge cuando se tiene un "vacío cognoscitivo".

5. En la búsqueda del convencimiento judicial acerca de lo discutido en el proceso, tanto las partes como el juez deben mutuamente colaborar, lo que no supone sustituir a la parte, sino tan solo afirmar su compatibilidad.

1 Revista Jurídica Bodas de Plata 1968-1993, Facultad de Derecho de la Universidad San Martín de Porres, Instituto de Investigaciones Jurídicas, 1993. Pág. 141.

2 Intervención en las Cuartas Jornadas Latinoamericanas de Derecho Procesal de Caracas, 1967.

3 El Derecho Procesal entre el Garantismo y la Eficacia: un debate mal planteado. En: Revista lberoamericana de Derecho Procesal, Instituto Iberoamericano de Derecho Procesal. Buenos Aires: 2004, Año III- ${ }^{\circ} 4$. Págs. 253 y 254.

4 La prueba en el proceso civil. 2da. edición actualizada. Buenos Aires: Abeledo - Perrot, 1992. Págs. 37 y 42.

5 Barcelona : Bosch Editor, 1996. Págs. 267-271.

6 V.g. Calamandrei, Couture, Denti, Cappeletti y otros.

7 Fondo de Desarrollo Editorial. Lima, 2005. Págs. 233-246.

8 Proceso penal y derechos humanos. La influencia de la normativa supranacional sobre derechos humanos de nivel constitucional en el proceso penal argentino. Centro de Estudios Legales y Sociales. Del Puerto. Buenos Aires, 2000, Pág. 185; citado por García Ramírez, Sergio. Elementos del debido proceso en la Jurisprudencia Interamericana de Derechos Humanos. En: Revista Iberoamericana de Derecho Procesal $\mathrm{N}^{\circ}$ 9. Año VI. Instituto Iberoamericanos de Derecho Procesal, 2006. Pág. 45.

9 Segunda edición. Bogotá: Ediciones Jurídicas Gustavo lbáñez, 1994. Págs. 103-105

10 Casación N $\mathrm{N}^{\circ}$ 673-2000-Lima, de fecha 4 de mayo de 2000.

11 Casación N $\mathrm{N}^{\circ}$ 2057-99-Lima, de fecha 8 de junio del 2000.

12 Ver Casación $\mathrm{N}^{\circ}$ 3639-2000-Cajamarca, de fecha 18 de marzo de 2000.

13 Ver Casación N ${ }^{\circ}$ 984-2005-Lima, de fecha 21 de marzo de 2006.

14 Ariano Deho, Eugenia. Poderes probatorios del juez y sus paradojas. En: Cuadernos Jurisprudenciales, Suplemento Mensual de Diálogo con la Jurisprudencia No 42. Lima: Gaceta Jurídica, 2004. Pág. 21.

15 Herencia Ortega, Inés Gabriela. Las pruebas de oficio frente al principio de preclusión en el proceso civil. En: Actualidad Jurídica, setiembre 2005. Lima: Gaceta Jurídica. Pág. 56. 